\title{
Communication Behavior in an Emerging Democracy
}

\author{
Political Expression via Tweets during the 2014 Tunisian Elections
}

\author{
Andrea Kavanaugh \\ kavan@vt.edu \\ Virginia Tech \\ Blacksburg, Virginia \\ Liuqing Li \\ liuqing@vt.edu \\ Virginia Tech \\ Blacksburg, Virginia
}

\author{
Ziqian Song \\ ziqian@vt.edu \\ Virginia Tech \\ Blacksburg, Virginia \\ Edward A. Fox \\ fox@vt.edu \\ Virginia Tech \\ Blacksburg, Virginia
}

\begin{abstract}
During elections in emerging democracies, communication behavior can indicate the relative freedom of expression perceived by individuals and organizations. Communication is critical for citizens to stay informed and make sense of competing political visions, platforms, and candidates. In Fall 2014, three years after the Arab Spring uprising that originated in Tunisia and resulted in the overthrow of long-time dictator Ben Ali, Tunisian citizens went to the voting booth to elect members of parliament and the next president. These were the first regular presidential elections since the Tunisian Revolution of 2011 and the adoption of the Constitution in January 2014, and the first free and fair presidential elections since independence from French colonialism in 1956. To explore the level of political tolerance and freedom of expression in this emerging democracy, we examined the contents and metadata of tweets during the election period. We used computational techniques (e.g., natural language processing, topic modeling, data visualization, and social graphing) as well as manual inspection of tweets to identify the main topics of political discussion and related social interaction. Our findings show a lively and open expression of political opinions, candidate positions, and policy issues appearing during the period of the 2014 elections, suggesting an increasingly democratic society in Tunisia.
\end{abstract}

\section{CCS CONCEPTS}

- Computing methodologies $\rightarrow$ Machine learning; $\bullet$ Humancentered computing $\rightarrow$ Empirical studies in collaborative and social computing;

\section{KEYWORDS}

social media, political participation, Tunisia, topic modeling, social graphing

Permission to make digital or hard copies of all or part of this work for personal or classroom use is granted without fee provided that copies are not made or distributed for profit or commercial advantage and that copies bear this notice and the full citation on the first page. Copyrights for components of this work owned by others than ACM must be honored. Abstracting with credit is permitted. To copy otherwise, or republish, to post on servers or to redistribute to lists, requires prior specific permission and/or a fee. Request permissions from permissions@acm.org.

dg.o 2019, June 18-20, 2019, Dubai, United Arab Emirates

(c) 2019 Association for Computing Machinery.

ACM ISBN 978-1-4503-7204-6/19/06 . \$ \$15.00

https://doi.org/10.1145/3325112.3325263
ACM Reference Format:

Andrea Kavanaugh, Ziqian Song, Liuqing Li, and Edward A. Fox. 2019. Communication Behavior in an Emerging Democracy: Political Expression via Tweets during the 2014 Tunisian Elections. In dg.o 2019: 20th Annual International Conference on Digital Government Research (dg.o 2019), June 1820, 2019, Dubai, United Arab Emirates. ACM, New York, NY, USA, 11 pages. https://doi.org/10.1145/3325112.3325263

\section{INTRODUCTION AND RELATED WORK}

Tunisia is the first country that initiated in December 2010 what became known as the Arab Spring, a series of cascading popular political movements that spread to Egypt, Libya, Bahrain, Yemen and Syria [16, 23]. Protests and violent demonstrations originated in the rural town of Sidi Bouzid on December 18, 2010, and spread throughout Tunisia to its capital, Tunis, largely due to the participation of young well-educated adults [22, 49], labor unions, and satellite-distributed news and videos broadcast by the Qatar-based Al-Jazeera Television Network [12, 18, 38].

For the most part, the Tunisian government-controlled media did not cover the 2010-11 uprising. Under the authoritarianism of the 23-year regime of President Ben-Ali, the mass media were strictly censored, and political talk and discussion brutally repressed [9, 40]. After 29 days of violent street protests, on January 14, 2011, President Zine El Abidine Ben Ali resigned and went into exile in Saudi Arabia, ending his 23-year regime. Following his departure, press freedoms rose and the number and diversity of news outlets for broadcast media, such as, television, radio and newspapers, increased as did online news sources, as some previously blocked or filtered websites opened up and new ones were created [21, 29].

Access to information and opportunities for political discussion about political developments are critical, especially during times of upheaval or crisis, such as revolution and post-revolutionary transitions in government $[1,19,43]$. Political talk and discussion whether formal or informal and online or offline are fundamental forms of democratic participation [27, 39]. Discussion and interaction take place not only face-to-face and over the telephone, but also online, and increasingly via social media, such as Facebook, Twitter, blogs, Instagram, YouTube and other user sharing applications.

Political talk depends on government tolerance, if not active support, of a relatively free press (for reliable information) and of freedom of expression among the populace (for discussion and deliberation) [31]. Citizens' free discussion of public issues is the 
defining criterion of a deliberative, democratic political system [27, 33]. The four interrelated components of deliberative democracy are: news media use, political conversation, opinion formation and political participation. Use of news media is associated with more frequent political conversation; use of news media and political conversation have positive effects on the quality of opinions (e.g., argument quality); news media use and political conversation affect willingness to argue with opponents; and news media use and political conversation are associated with participation, notably with "campaigning" rather than "complaining" [27].

Political participation theory explains the various motivations among different types of people and organizations to engage (or not) in civic and political life $[2,13]$. Keeping up with news, sharing information issues with others are all forms of political participation, including online variations of these behaviors [10, 39]. For democratic participation, an informed citizenry is essential to opinion formation and consensus building [33, 48].

Political discussion network theory seeks to explain political conversation and social interaction about politics and issues of interest $[35,50]$. Some people never or rarely discuss politics with anyone. Other people only discuss politics with strong social ties, that is, trusted members of their social network, such as, close friends and family; some people also discuss politics with their weaker social ties, such as acquaintances and friends of friends. Measures of political discussion include 1) frequency (e.g., never/rarely to several times a day), 2) number and type of discussion network members (e.g., no one or only immediate family to many), 3) heterogeneity of discussion network members (e.g., level of similarity in world view to the respondent, similarity in agreement on issues, and similarity in extent of knowledge about issues or candidates).

The most active discussants about politics (and many other topics) are opinion leaders - the extroverted, innovative risk-takers that exist at all social strata and influence members of their social networks by sharing their ideas and advice online and in person [26]. They are also the most avid users of social media, especially Twitter [41].

People who engage in public expression via social media, largely tend to see themselves as opinion leaders, at least within their social networks and often more widely [44], and to engage with news media more generally [3]. They have been found to affect narratives about political issues and the strategies of political institutions [11] The wide use of social media has made it easier for the people who only speak about politics with close friends and family to engage more frequently in political talk online, especially via social network platforms, such as Facebook [31]. Studies in the US have shown that political expression leads people to participate politically further in other forms, both online and in person, such as, campaigning for an issue or candidate [17, 36, 37].

Political conversation is riskier in heterogeneous discussion networks because disagreement is more likely among diverse members who may respond with disapproval, criticism, or confrontation [31]. Under authoritarian regimes, such as pre-2011 Tunisia, where censorship and repression were routine, political expression was much more constrained and circumspect, since criticism of the government or Islam was typically met with reprisal, arrest, or worse.
Freedom of expression is not only a democratic ideal, it is a legally formalized right (or not) stipulated in resolutions and constitutions [33]. In the US Constitution's First Amendment, freedom of expression is comprised of freedom of speech, the press, assembly and petition. When citizens sense their government has low tolerance for political discussion, they are naturally more likely to refrain from speaking their minds $[31,40]$ which extends to online "talk" as well (e.g., blogging, microblogging or tweeting, and Facebook posts). Conversely, frequent and active political exchange online suggests that participants sense there is adequate freedom of expression for them to share and interact online without threat of arrest or imprisonment [28, 30, 43, 46, 47]. Thus, social media posts represent a canary in the mine; they are a reasonable indicator among others - of the level of political tolerance and freedom of expression perceived by participants in an emerging democracy.

During post-revolutionary government transitions, such as the 2014 elections in Tunisia, different actors seek to influence discussion, collective sense-making and public participation. The perceived freedom of expression among participants is a key factor in evaluating whether the emerging social and political tendencies are moving toward more democratic or more authoritarian processes [33].

Our research question is the following: Is post-revolutionary Tunisia tending toward more democratic or more authoritarian communication processes? We answer this question by investigating evidence for political expression during the 2014 Tunisian elections as portrayed in tweets.

To explore the level of political tolerance and freedom of expression in Tunisia three years after the 2011 revolution, we examined the tweet contents and some of the metadata of tweets posted during the 2014 parliamentary and presidential campaigns and elections. We analyzed a collection of tweets we had created as part of a larger set of collections on Tunisia and terms related to elections. We used computational techniques, including natural language processing, topic modeling, data visualization, and social graphing, as well as manual inspection of tweets, to identify the main topics of tweets and social interactions among users during the period of the 2014 elections in Tunisia: October through December 2014.

Studies of Twitter communication [8] show that re-tweeting and @mentioning others' tweets and accounts can constitute a conversation among users. Smith and colleagues [42] further identified multiple patterns of Twitter networks representing different types of conversations based on the size and connectivity of clusters; these include: polarized crowds, tight crowd, community clusters, and broadcast networks. We use social graphing in this study to determine whether there appears to be conversations in our Twitter data, as well as the type of Twitter networks in our data about the 2014 Tunisian elections.

\section{POLITICAL AND ECONOMIC CONTEXT}

Tunisia is a small, upper middle-income country in North Africa with a population of 11.3 million at the time of the 2014 elections. It is a former French colony whose languages are predominantly French and Arabic. Tunisia's economy is highly dependent on foreign tourism. During the period of the revolution (2010-11) according to World Bank indicators [25] adult literacy was fairly high at 
79 percent, rising to 81 percent by 2015. GDP per capita in 2011 US dollars was 4,305 , and fell slightly to 3,872 by 2015 .

Total unemployment just before the uprising was about 13 percent and rose to 18 percent a year later, with the loss of some foreign investment and tourism after the uprising. Youth unemployment (ages 15-24) as a percentage of total labor force was high (29 percent in 2011 rising to 31 percent by 2015) and was especially high for educated youth $[16,25]$. The high unemployment rate of educated youth has been identified as one of the motivations for youth participation in the revolution [22].

Before turning to our Methods, we briefly summarize the results of the 2014 elections and the larger context of communication behavior (especially, Internet and social media use) in Tunisia.

\subsection{Parliamentary and Presidential Elections}

Young, educated Tunisians were credited with being an important influence in the uprising in 2011, along with their use of social media, especially Facebook (FB) [34]. The relatively independent Arab regional satellite TV broadcasting network, Al Jazeera, was also credited with carrying timely and reliable information and video footage of protests and demonstrations that rocked North Africa at the time (most notably, Egypt, Libya and Tunisia) [12, 24, $30,46]$. These groups together with the labor unions were major players in the uprising in 2011 [20,49].

The 2014 elections were the first regular presidential elections since the Tunisian Revolution of 2011 and the adoption of the new Constitution in January 2014. Both local and international monitors described the elections as "free and fair" with the secular parties winning and the Islamist parties conceding the election peacefully $[4,32]$.

The Parliamentary elections were held October 26, 2014. Presidential elections were held November 23, 2014, followed by a second round on December 21, 2014. In the parliamentary elections, the big tent Nida Tunis (Tunis Calls) party (also sometimes appearing as Nidaa Tounes), running on an explicitly more secular, anti-Islamist platform, won a plurality, 85 of the 217 seats. This plurality in parliament gives it the right to name a prime minister and to lead a coalition government.

The moderate Islamist Ennahda party (also written as al-Nahda), which had previously dominated the parliament, came in second with 69 seats [4, 32]. The Free Patriotic Union was a distant third with 16 seats; Slim Rihai, millionaire football club owner and political newcomer, heads the party. In fourth place was the left wing coalition of parties known as the Popular Front; extremists assassinated two of its members in 2013. The liberal Afek Tounes came in fifth place with 8 seats. The remaining 24 seats were split among a dozen small parties.

The Presidential elections went to a second round on December 21, 2014, in a run off between incumbent Moncef Marzouki, the Nidaa Tounes party's founding leader, and candidate Beji Caid Essebsi, who won with 55.68 percent of the final vote [5].

\subsection{Internet and Social Media Use}

The Tunisian revolution in 2011 gave birth to greater press freedoms and news outlets for broadcast media, such as, television, radio and newspapers, as well as new online news sources, and opened up access to some blocked or filtered websites, such as, www.nawaat.org, YouTube.com and dailymotion.com [21, 29]. Internet penetration in Tunisia at the time of the uprising (end of 2010, early 2011) was estimated at 36.8 percent, rising to 43.8 percent in $2013[25,28]$. Around the time of the 2014 elections reported here, Internet penetration had risen to almost half ( 48.5 percent) of the population [25].

In general, in the Arab world, during the period between 2010 and 2015, the percentage of Facebook (FB) users that were young people (aged 15-29) had been much higher than the percentage of total FB users over the age of $15[34,38,45]$. That is, as in some other parts of the world, young people were the predominant users of Facebook. Moreover, there has been a long-time youth bulge in Tunisia, as in many other countries in the Middle East [14]. Thus, in Tunisia, young people (15-29 years old) in 2014 made up 37.5 percent of the total population over 15 years old, and the majority (77.7 percent) of FB users [38]. During the elections, citizens predominantly used the Internet, including social media, and especially Facebook, to find information and to share what they found online with their trusted network of family and friends.

As for gender and language, there were more male than female FB users as a percentage of total FB users (58 percent male) in Tunisia. Facebook penetration rose to 85 percent by 2015 from 33.9 percent in 2013 and a mere 17.6 percent in early 2011 at the time of the uprising $[34,38]$. The primary language is Arabic, followed by French, with English a distant third.

Twitter penetration, by contrast, was low and remained steady in Tunisia between early 2011 and late 2014 (0.34 percent) when there were an estimated 35,746 users. The small increase in the number of Twitter users (estimated in 2014 at 37,100) is offset by the small increase in population, thereby keeping Twitter penetration (number of users per 100) roughly the same for four years [38, 45]. While very few Tunisians used Twitter, the low penetration is offset by the expectation that many Twitter accounts are held by opinion leaders and other influential individuals whose impact on members of their social circles is well-established as substantial.

We collected Twitter data rather than Facebook (FB) data because relevant FB data (that of individual citizens) is typically in personal accounts protected by passwords and thus inaccessible.

\section{METHODS}

We created a data set of tweets extracted from several larger tweet data collections that we had generated starting in early 2011 and since. Based on the resulting relevant tweets, we leveraged an unsupervised topic modeling method to generate topics. We used several computational techniques, including natural language processing and topic modeling and visualization, as well as social graphing based on retweets and @mentions.

Most of the tweets in our extracted three-month collection are in English. In this paper we focus on the small proportion (about $11 \%$ or about 31,000 tweets) that are in Arabic, because this set of tweets reflects a more internal conversation among Arab speakers. As such, communication in Arabic would be a better indicator of freedom of expression locally and in the region. 


\subsection{Twitter Data Collection and Processing}

We have been collecting Twitter data related to Tunisia in real time since 2011, as part of a larger project [omitted]. We have been using both YourTwapperKeeper (YTK) and Social Feed Manager (SFM) to create and store the collections as part of a 22-node Hadoop cluster at [omitted] university.

For this paper, we created a new dataset from four collections related to Tunisia in order to obtain data related to the 2014 elections, as described below.

1) From a larger collection using the term 'tunisia' we extracted all tweets during the period of the elections (October 1, 2014 through December 31, 2014). This produced 307,000 tweets. Not all the tweets during this period were about the elections, of course.

2) We extracted tweets from a larger collection on the term 'election' that contained the term 'tunisia' in the tweet for the period of the 2014 Tunisian elections; this produced 8,888 tweets.

3) At the outset of the election period, in early October 2014 we created a separate collection using the hashtag \#tunisianelections through December 2014. This produced 1,153 tweets.

4) We extracted tweets from a larger collection on the hashtag \#election2014 that had the term 'tunisia' in the tweet, obtaining only 121 tweets.

We removed tweets sent by advertisers and similar spam accounts. After cleaning, there were 310,598 tweets in our collection sent by 99,411 Twitter accounts.

\subsection{Topic Modeling and Data Visualization}

Topic models are algorithms for identifying the primary terms or themes in a large dataset or collection of documents. Topic modeling algorithms are statistical methods to analyze words in a large dataset and to discover connections among words, including how they change over time [6,7]. In our analyses, we divided the topic modeling process into three parts: natural language processing (NLP), latent dirichlet allocation (LDA), and front-end visualization (FEV).

In the first stage, we used NLTK, a widely used symbolic and statistical NLP software program, to tokenize each tweet into terms. In order to get higher quality data, we eliminate the following terms that are unhelpful for topic modeling: 1) 'stop words' in English and Arabic (e.g., prepositions, articles, and conjunctions), 2) short URLs, 3) account names mentioned (e.g., @twitter), and 4) terms that are fewer than 4 characters in length.

Then we used an open source software called Gensim to automatically detect topics in the LDA stage. It is designed for plain text mining and can be easily applied to our tweet scenario. By configuring the parameters in Gensim, we are able to modify the total number of topics, and the number of topics or words in each document. We tested the topic modeling with four topics and with six topics to evaluate a useful topic limitation.

In the final stage, we use LDAvis, a data visualization library to explore, interpret and visualize LDA topic results. LDAvis maps the topic similarity by calculating a semantic distance between topics. For this study, we created a Jupyter notebook for LDA vis. Jupyter is a web application for running live code, embedding visualizations and explanatory text in one place.
We ran the topic modeling separately on the English versus the Arabic tweets since these are likely to be domestic and regional users versus international users. We also wanted to test whether the topics were similar in both languages. Given our interest in the domestic and regional Twitter users during the 2014 elections, we focus in this paper on the Arabic topic modeling.

\subsection{Social Graphing}

A graph is a set of points (nodes or vertices, such as, user accounts) connected by lines (also referred to as edges). Graph degree is the number of connections between graph nodes [15]. We used NodeXL software to create social graphs of our all user accounts (whether English, Arabic or French) that are connected to each other by retweets and/or @mentions. For the social graph visualization, in order to improve sense-making, we removed tweets sent by accounts that published fewer than 5 tweets; this left a total of 103,383 tweets included in these analyses. In our graph we show the names of the user accounts with higher measures of interactions (i.e., graph degree greater than 30). Accounts with lower measures of interactions (i.e., graph degree less than 30) are shown as nodes, but not labelled with the name of the account.

In order to get a sense of how much interaction and "informal discussion" was evident among all our Twitter users, we calculated the number of interactions (based on retweets and @mentions) for the top most frequently used hashtags. To simplify the counts, we combined some hashtags that are very similar, such as Tunisia and tunisia, or TnElec and tunisianelections. We did not combine hashtag counts that used the English spelling of "Tunisia" with the French spelling "Tunisie" since these users may be distinct types of users (i.e., English or French speakers). Given that French is the main language in Tunisia after Arabic, tweets in French could have been generated locally (or across the French speaking region known as the Maghreb in North Africa). We provide the count of a given hashtag, the number of users who shared that hashtag, the number of interactions (retweets and @mentions) related to the hashtag, and the number of unique accounts engaged in the interactions.

\section{RESULTS}

\subsection{Topic Modeling and Data Visualization}

For the topic modeling of our Arabic Twitter dataset, we found that a limit of four topics gave us more recognizable, distinct topic clusters than six or more topics limitation. Of the four distinct topics, three are clearly about the 2014 elections. A fourth topic is focused on soccer matches for the Africa Cup, which was underway at that time.

Topic 1 (Figure 1): Words most commonly used: Media, Reporting, Elections, Tunisia, Marzouki (candidate name). This topic seems to be largely about media reporting, such as, updates on status of competitions among candidates; for example:

- Initial Indicators that "Essebsi" will win;

- "Essebsi" is leading with a score of $90 \%$;

- Tentative Results for who is the winner in different cities (e.g. Sfax).

Topic 2 (Figure 2): Words Used most commonly used: Elections, Authority, Essebsi, Beji, Caid, Marzouki: This topic seems to be largely about the candidates for Presidential elections in Tunisia 


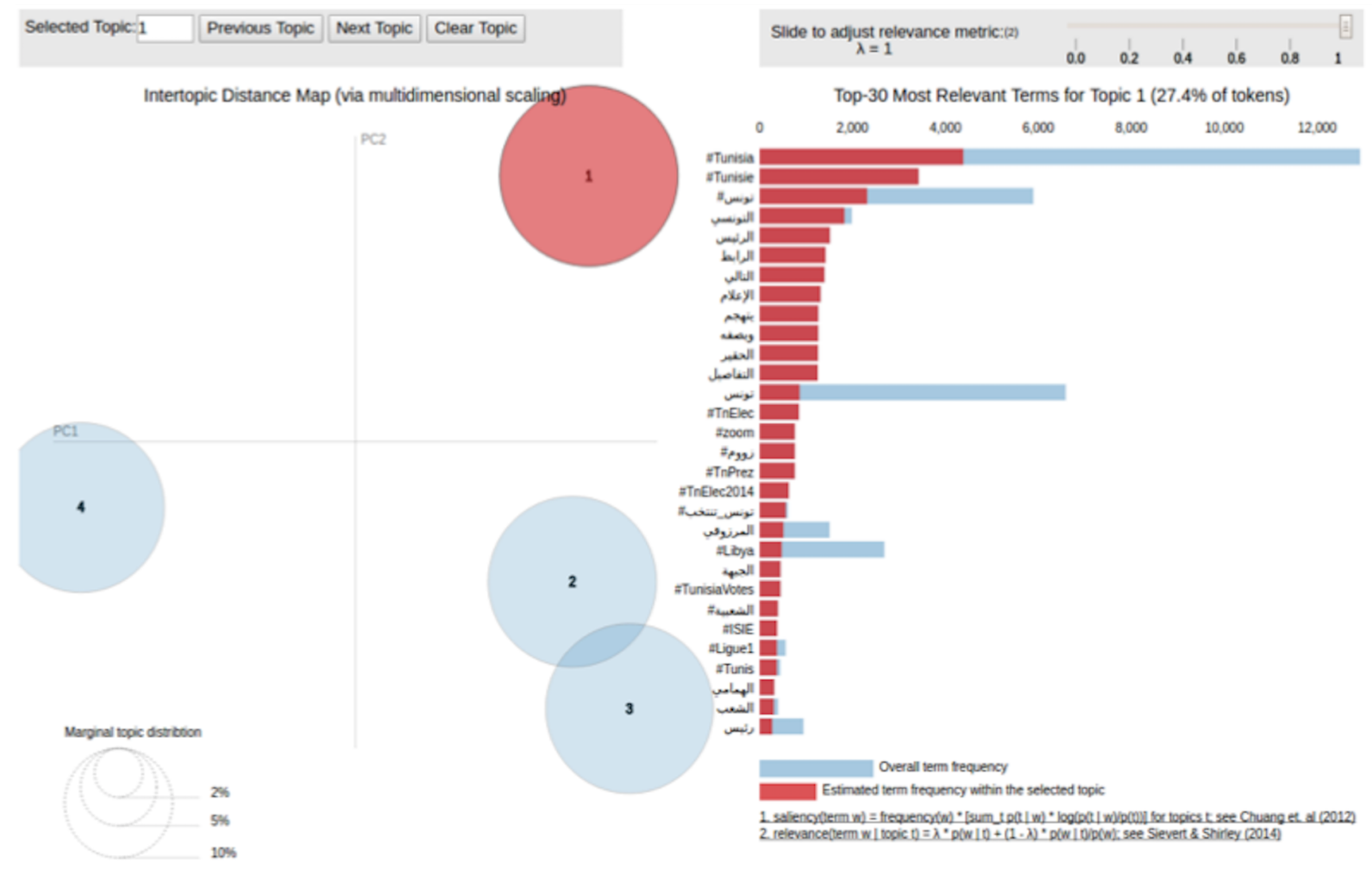

Figure 1: Topic One in Arabic (Election Reporting)

2014, for example: the individual words, as follows:

- Essebsi, Beji, Caid: refers to Beji Caid Essebsi which is the name of one of the candidates, specifically, the winner of the election for president.

- Marzouki: refers to Mohamed Moncef Marzouki, former Tunisian President (2011-2014), one of the two top candidates, who lost in the second round of the presidential election.

Topic 3 (Figure 3): Words used: Al-Nahda, movement, elections, presidential: This topic appears to be about the Islamic "Al-Nahda" movement and political party; for example: Al-Nahda "Uprising" referring to the Islamic party and movement in Tunisia; "Movement" referring to the Islamic "Al-Nahda" party and Islamic platform and supporters in Tunisia.

Topic 4 (Figure 4): Words used: Football Matches, Following (Matches), Watching (Matches), Qualifications for African Cup of Nations. This topic is clearly distinct from the other three; it is about the soccer matches, teams and countries in the African Cup of Nations.

Our topic modeling of the English language tweets showed very similar topics as those in Arabic. The main difference is in the fourth topic. In Arabic tweets, the fourth topic is about the Africa Cup; in English the fourth topic is about music and life generally.

\subsection{Social Graphing}

The social graph of retweets and @mentions (Figure 5) of all our tweets for the three-month period of the elections shows two very large clusters of interaction among accounts, with multiple smaller clusters with fewer accounts. Most of the clusters show a lot of connections across groups, as well. This is due to the retweet or @mention of an account in a different cluster, albeit less often than within each cluster.

In Figures 6 and 7 we focus on the two largest clusters, Group 1 and Group 2, respectively. The top accounts in these two groups, ranked by degree, are further described in Table 1 . The account descriptions and interests are based on our manual inspection of top ten accounts (by degree). For Group 1, the second column in Table 2 shows the description provided by the account owner (admittedly abbreviated to fit the Table). The third column in Table 2 shows the summary words we wrote to describe the typical topics of the user's tweets within our collection at the time of the 2014 elections. The same sequence applies to the Group 2 portion of Table 1.

Many of the accounts in these two large groups are organizational and pertain to political information, themes or purposes. One of the top Twitter accounts has been suspended (e.g., Khaffousa), and another (mmc tunisia) is no longer available, although we do not know why. A manual inspection of our archived tweets in the Khaffousa account show many tweets related to politics and the election; it is possible the account was suspended (possibly even by Twitter) due to the use of some off-color words.

In Table 2 we show the top hashtags used during the election period, and the number of interactions (based on retweets and @mentions) around those hashtags. For example, the first hashtag \#Tunisia, was used 74,595 times during the three month period, by 


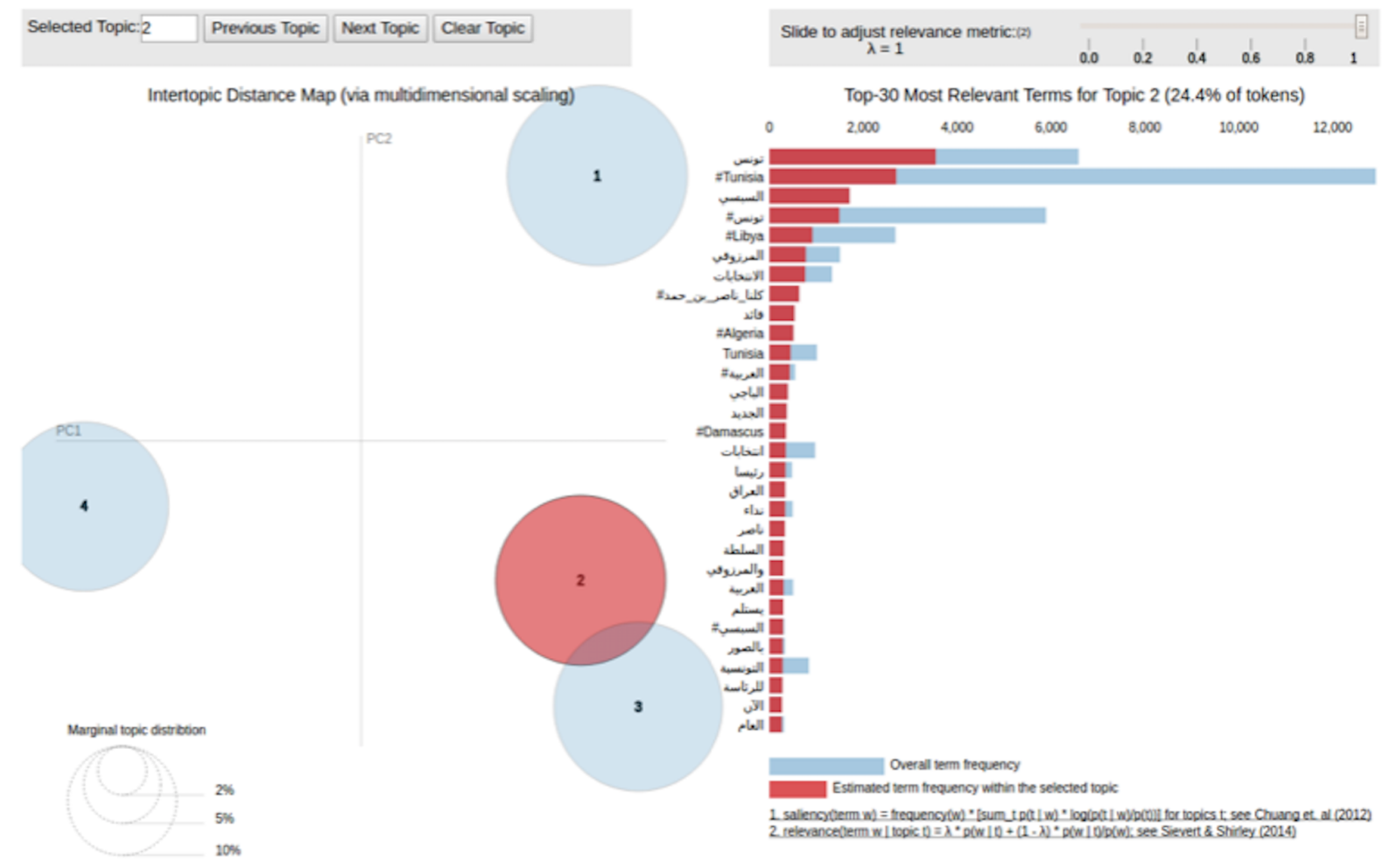

Figure 2: Topic two in Arabic (Candidates)

25,214 users. The number of retweets and @mentions with this hashtag was 47,136 by 32,688 unique users.

\section{DISCUSSION AND CONCLUSION}

In this paper we show findings from our investigation of Twitter content generated during the three-month period of the 2014 parliamentary and presidential elections in Tunisia. We collected tweets using several terms and hashtags related to Tunisia since the 2011 uprising and revolution. For the analyses reported in this paper, we extracted all tweets from our larger collections on the term "Tunisia" and "elections" within the time period October 1 through December 31, 2014.

The main question of our study regards the presence or absence of political expression during these elections in Tunisia, given the competing political interests and sometimes violent conflict (e.g., political assassinations, street protest and clashes) in the aftermath of the 2011 revolution that ended the 23-year dictatorial regime of President Ben-Ali.

In this paper we focus on the proportion (about $11 \%$ ) of our total collection on the 2014 elections that are in Arabic, because this set of tweets reflects a more internal conversation among Arab speakers. The fact that there is active discussion not only in French or English, but also in Arabic, further suggests that local participants perceived it to be safe to express themselves within Tunisia and the region. Prior studies [28] have argued that during the Arab Spring, tweets in English suggested the author was seeking to communicate with an international audience; many English language tweets were observed early in the uprising period (2011-12) across multiple countries. However, tweets in Arabic suggest more domestic and regional audiences. The tweets we find in Arabic would therefore indicate that these discussions were intended for fellow Tunisians and regional neighbors.

Our topic modeling shows that three out out of four of the main topics in Arabic in our data set pertain to the elections, indicating interest in and freedom of expression about politics in Tunisia. This suggests that there is a basic sense among users that they can express their political opinions relatively freely and safely. It is noteworthy that the topic modeling for the English language tweets are similar to the Arabic (that is, they pertain to the elections).

Our social graph of accounts connected by retweets and @mentions produces two large clusters and multiple smaller clusters. The two large clusters (Groups 1 and 2) are highly connected with retweets and @mentions across the two groups, which suggests that this is not a highly polarized pattern of conversation. Both large groups are tweeting about politics at least occasionally and retweeting and @mentioning others in their group and others across groups. This suggests a lot of interaction and informal discussion or conversation on mainly political themes among users. The number of interactions around most of the hashtags is fairly high, and suggests that users were actively engaged in exchanges on these political themes.

Our findings from the topic analysis and social graphs indicate a relatively high level of free speech around the Tunisian elections in 2014. Our results strengthen the argument that tweet data can 


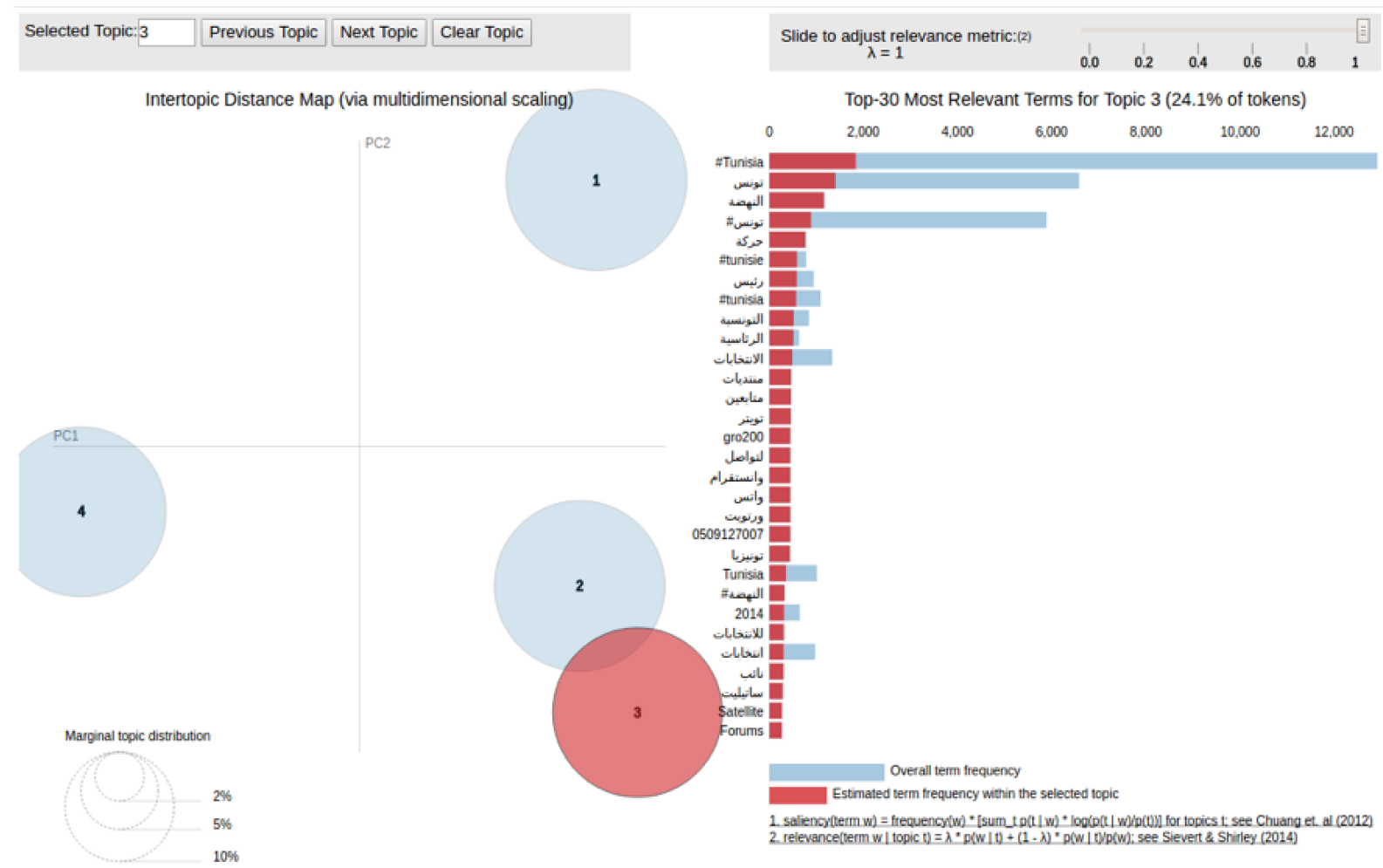

Figure 3: Topic three in Arabic (Politics)

Table 1: Top 10 Accounts in Group1 and Group2 ranked by Graph Degree ${ }^{1}$

\begin{tabular}{|c|c|c|c|c|c|}
\hline Group1 & Account Description & Interests & Group2 & Account Description & Interests \\
\hline EnnahdhaParty & $\begin{array}{l}\text { Official account of En- } \\
\text { nahdha Party }\end{array}$ & Politics & FRANCE24 & International News & General News \\
\hline mmc_tunisia & Account Not Available & $\begin{array}{l}\text { General Life, } \\
\text { Occasional } \\
\text { Politics }\end{array}$ & HF_Tunisia & Mining and Transport Co & General News \\
\hline Tunisia_Live & Tunisian News Website & $\begin{array}{l}\text { Tunisia Elec- } \\
\text { tion, Politics }\end{array}$ & wheelertweets & $\begin{array}{l}\text { Libya, Tunisia, MENA, EU, USA, } \\
\text { World }\end{array}$ & $\begin{array}{l}\text { Terrorism, Mili- } \\
\text { tary, Politics }\end{array}$ \\
\hline Khaffousa & Account Suspended & $\begin{array}{l}\text { Tunisia Politics, } \\
\text { Terrorism }\end{array}$ & TheEconomist & $\begin{array}{l}\text { News and analysis with a global per- } \\
\text { spective }\end{array}$ & Tunisia Politics \\
\hline walidsa3d & Technologist & Tunisia News & TEDxEuston & Afican Ideas Sharing & Tunisia News \\
\hline NaveenaKottoor & $\begin{array}{l}\text { Redakteurin, } \\
\text { Chefredaktion, dpa }\end{array}$ & Tunisia Politics & AlArabiya_Eng & Al Arabiya network & $\begin{array}{l}\text { Tunisia Elec- } \\
\text { tion }\end{array}$ \\
\hline ZiZiRiDeR69 & Sex and Politics & $\begin{array}{l}\text { Tunisia Daily } \\
\text { Life }\end{array}$ & nytimes & $\begin{array}{l}\text { news, special reports, RTs of our } \\
\text { journalists }\end{array}$ & $\begin{array}{l}\text { Concerns for } \\
\text { Tunisia }\end{array}$ \\
\hline ImadMesdoua & Political Analyst & Tunisia Politics & Annoula64 & Peace, equity, justice for all & $\begin{array}{l}\text { Tunisia, Human } \\
\text { Rights, Extrem- } \\
\text { ists, Terrorists }\end{array}$ \\
\hline yasmineryan & $\mathrm{NZ}$ journalist & $\begin{array}{l}\text { Tunisia Elec- } \\
\text { tion }\end{array}$ & AodiFoad & $\begin{array}{l}\text { Founder, Association of Doctors of } \\
\text { Foreign Origin (AMSI) }\end{array}$ & $\begin{array}{l}\text { Some Political } \\
\text { Commentary }\end{array}$ \\
\hline tunisia_decrypt & $\mathrm{N} / \mathrm{A}$ & Terrorism & BBCWorld & World News, features and analysis & Tunisia News \\
\hline
\end{tabular}

${ }^{1}$ The graph degree is calculated by the number of edges associated with the vertex 


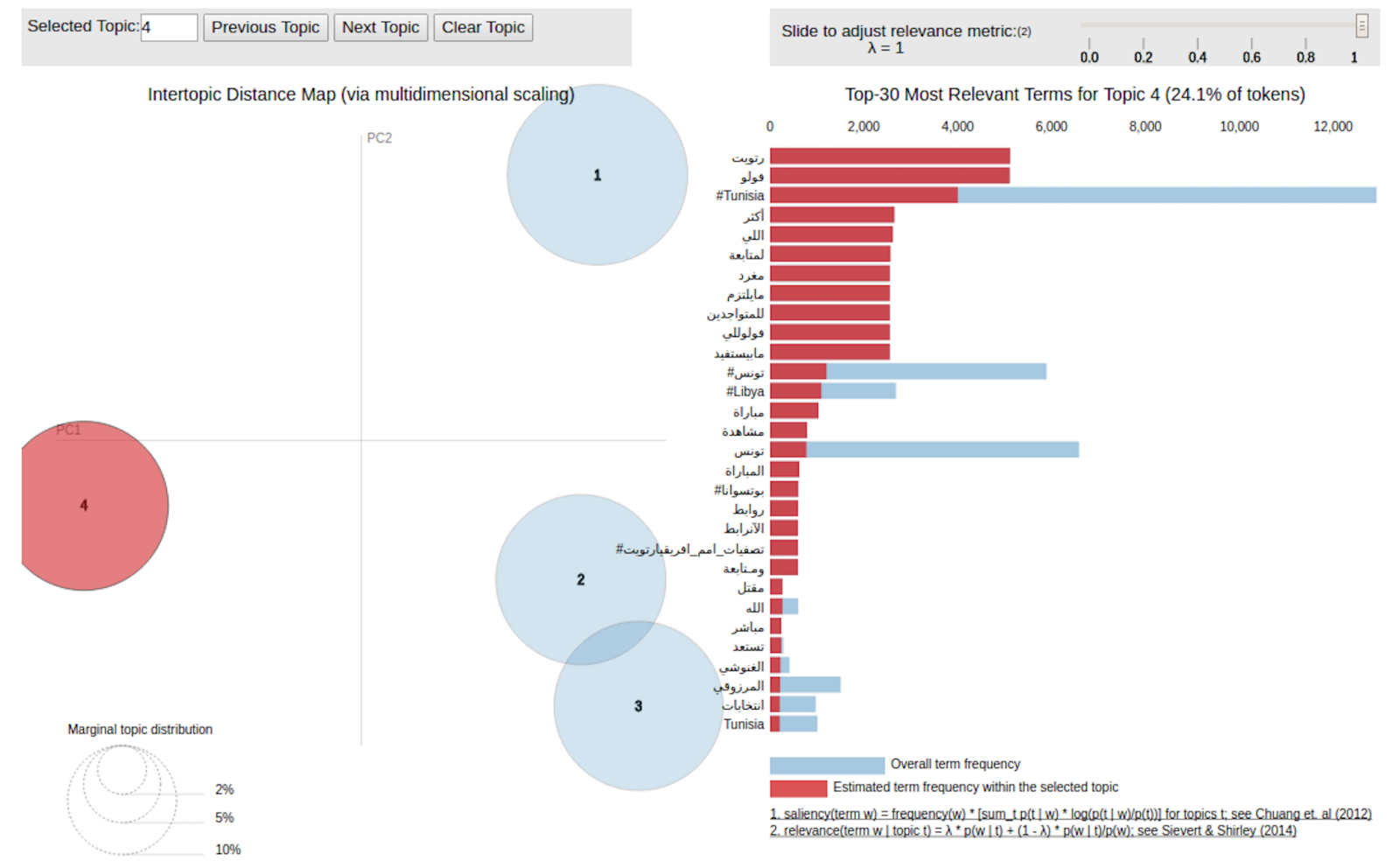

Figure 4: Topic four in Arabic (Soccer)

Table 2: Top Hashtags and Interactions

\begin{tabular}{ccccc}
\hline Hashtag & Frequency & UserCount & Interaction & UserInteract \\
\hline Tunisia $^{1}$ & 74595 & 25214 & 47136 & 32688 \\
TnElec $^{2}$ & 13339 & 4490 & 7429 & 5747 \\
Tunisie $^{3}$ & 12534 & 2726 & 4856 & 3580 \\
S.Pana? & 12259 & 2425 & 3218 & 2746 \\
TnPrez & 4009 & 798 & 1644 & 1069 \\
Tunis & 1980 & 930 & 889 & 1211 \\
Ennahdha & 1443 & 633 & 1167 & 711 \\
AFCON2015 & 1191 & 871 & 930 & 984 \\
Essebsi & 1019 & 629 & 690 & 760 \\
ArabSpring & 635 & 494 & 487 & 644 \\
democracy & 598 & 507 & 512 & 658 \\
Marzouki & 566 & 384 & 416 & 493 \\
\hline
\end{tabular}

Note: 1 . Counts include \#Tunisia, \#tunisia and \#TUNISIA; 2.

Counts include hashtags related to Tunisia elections: \#TnElec, \#TunisiaVotes, \#TnElec2014, \#Tnelec, \#tnelec and

\#tunisianelections; 3. Counts include \#Tunisie and \#tunisie; 4. Counts includde \#Tunis and \#tunis;

indicate relative freedom of expression in emerging democracies. They also contribute to studies of communication behavior (i.e., social media use for informal political discussion and information sharing) by citizens and organizations following revolution and political crisis.

\section{ACKNOWLEDGMENTS}

We are grateful to the National Science Foundation (NSF) for its support of the larger [name omitted] project of which this work is part [omitted grant number]. Any opinions, conclusions, and findings or recommendations expressed here are those of the authors and do not necessarily reflect the views of NSF. We are indebted to our graduate research assistants [omitted].

\section{REFERENCES}

[1] Ban Al-Ani, Gloria Mark, Justin Chung, and Jennifer Jones. 2012. The Egyptian Blogosphere: A Counter-narrative of the Revolution. In Proceedings of the ACM 2012 Conference on Computer Supported Cooperative Work (CSCW'12). ACM, New York, NY, USA, 17-26. https://doi.org/10.1145/2145204.2145213

[2] Gabriel A. Almond and Sidney Verba. 1963. The Civic Culture: Political attitudes and democracy in five nations. Princeton University Press, Princeton.

[3] Ike Picone Rasmus Kleis Nielsen Antonis Kalogeropoulos, Samuel Negredo. 2017. Who shares and commnets on news? A cross-national comparative analysis of online and social media participation. Social Media \& Society 3, 4 (2017), 1-12.

[4] AP. 2014. Tunisia Election Results: Nida Tunis wins most seats sideling islamists. https://www.theguardian.com/world/2014/oct/30/ tunisia-election-results-nida-tunis-wins-most-seats-sidelining-islamists

[5] BBC. [n. d.]. Tunisian election: Essebsi wins presidential run-off. https://www. bbc.com/news/world-middle-east-30579662

[6] David Blei. 2012. Probabalistic Topic Modeling. Commun. ACM 55, 4 (2012), 77-84.

[7] David Blei and John Lafferty. 2009. Topic models. Chapman \& Hall, London, UK.

[8] danah boyd, Scott Golder, and Gilad Lotan. 2010. Tweet, Tweet, Retweet: Conversational aspects of retweeting on Twitter. In Hawaii International Conference on System Sciences (HICSS-43). IEEE.

[9] Donald R. Browne. 1999. International Broadcasting in Arabic: Tunisia. Iowa State Universiy Press, 261-78.

[10] Andrew Chadwick. 2006. Internet politics: States, citizens, and new communication technologies. Oxford University Press, New York, NY. 


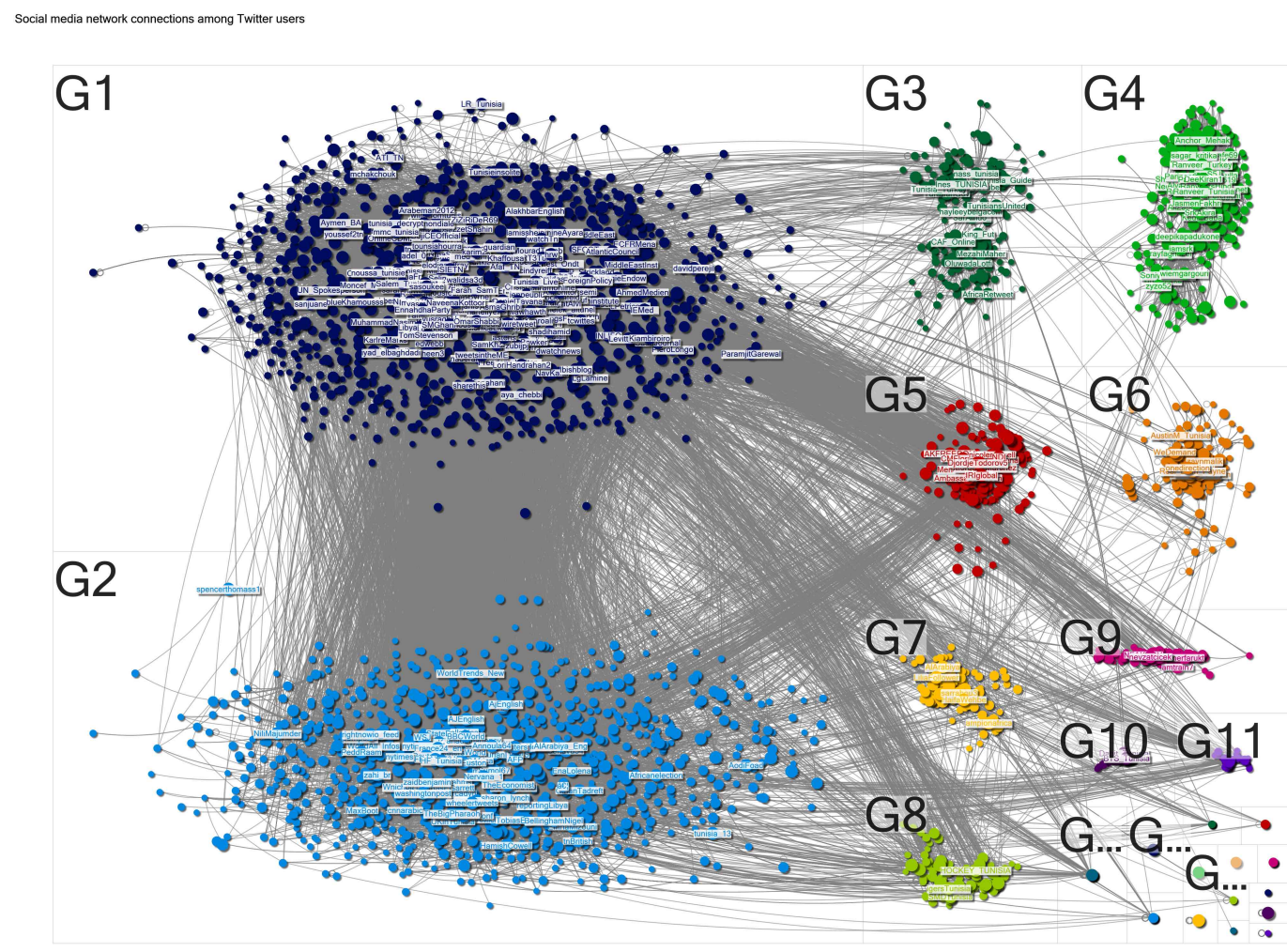

Figure 5: Social Graph Overview

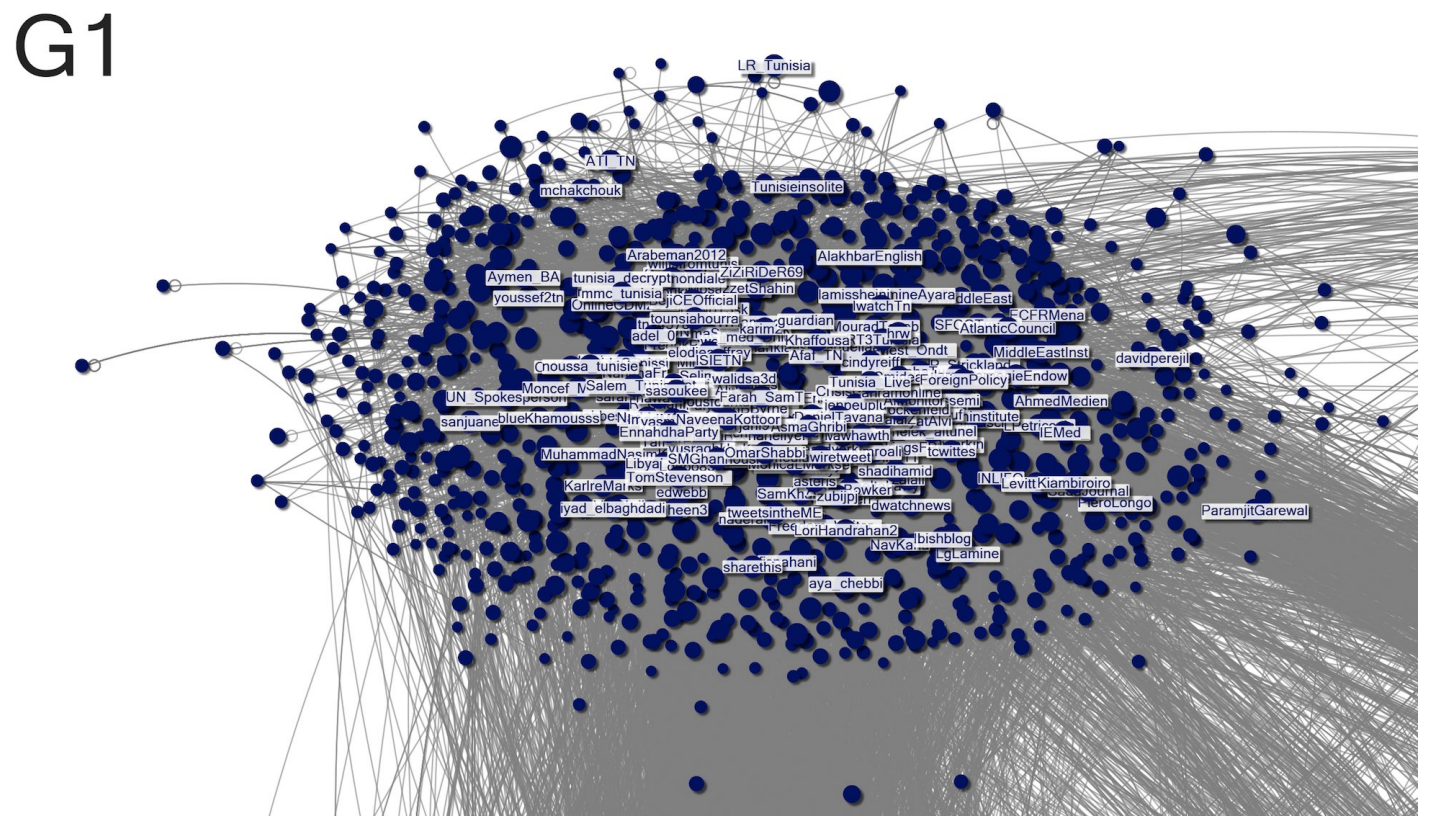

Figure 6: Social Graph of Group1 


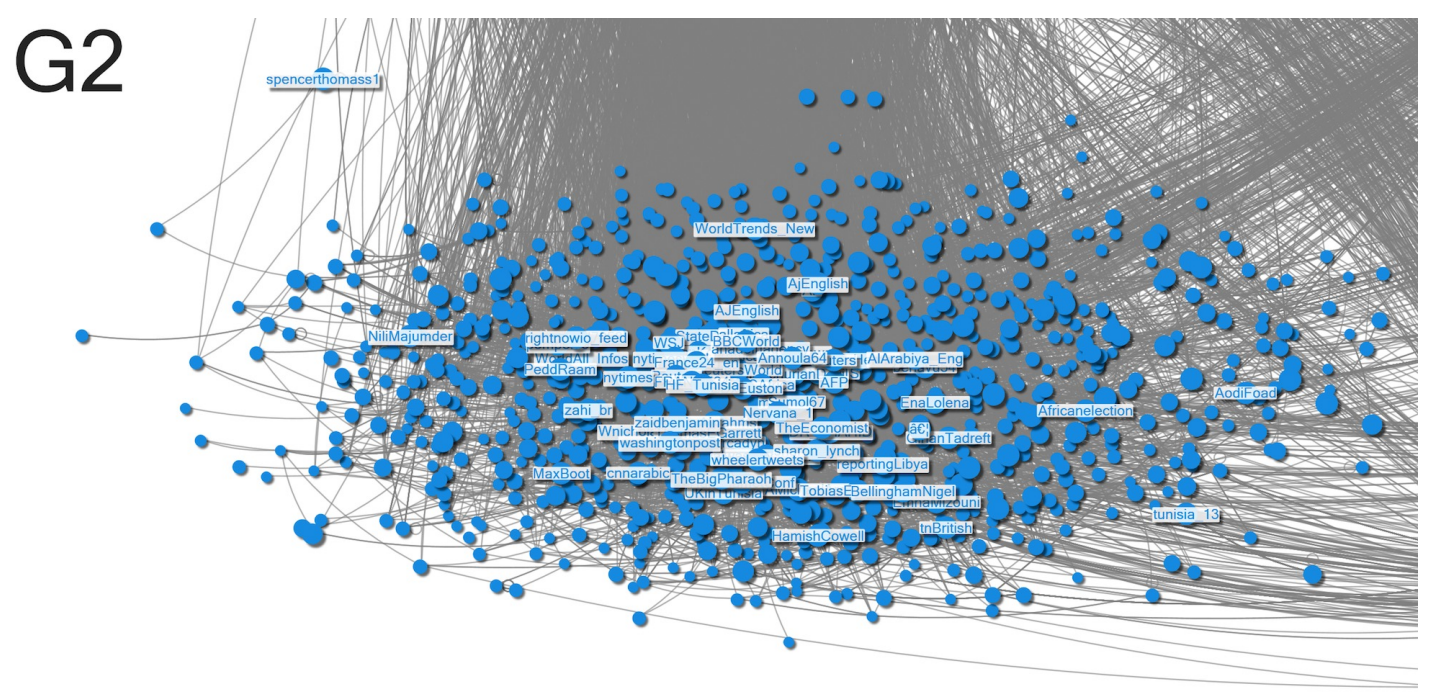

Figure 7: Social Graph of Group2

[11] Andrew Chadwick. 2017. The Hybrid Media System: Politics and Power. Oxford University Press.

[12] Sohail Dahdal. 2012. Social Media and the Arab Spring: The historical context and the role of Aljazeera satellite station. In Conference for E-Democracy and Open Government (CeDEM), Edelmann N. Parycek, P. and M. Sachs (Eds.). DonauUniversitat Krems, 219-228.

[13] Robert A. Dahl. 1989. Democracy and its Critics. Yale University Press, New Haven, CT.

[14] Navtej Dhillon and Tarek Youssef. 2009. Generation in Waiting: The unfulfilled promise of young people in the Middle East. Brookings Institution, Washington, DC

[15] Reinhard Diestel. 2016. Graph Theory (5th ed.). Springer-Verlag.

[16] Daniel Egel and Malek Garbouj. 2013. Socioeconomic drivers of the spread of the Tunisian revolution. Report. RAND Corporation and the Graduate Institute.

[17] Larry Elin. 2003. Cyberactivism: Online activism in theory and practice. Routledge, New York, NY, Chapter The radicalization of Zeke Spier: How the Internet contributes to civic engagement nd new forms of social capital, 97-114.

[18] Jeffrey Ghannam. 2012. Digital media in the Arab world one year after the revolutions. Report. Center for International Media Assistance (CIMA), National Endowment for Democracy.

[19] Edmund Ghareeb. 2000. New Media and the Information Revolution in the Arab World. The Middle East fournal 54, 3 (2000), 395-418.

[20] Rikke Haugbølle and Francesco Cavatorta. 2012. Beyond Ghannouchi: Islamism and social change in Tunisia. Middle East Report 262, Spring (2012), 20-25.

[21] Rikke Hostrop Haugbolle. 2013. Making of the Tunisian Revolution: Contexts, Architects, Prospects. Edinburgh University Press, Chapter Rethinking the Role of the Media in the Tunisian Uprising, 159-180.

[22] Alcinda Honwana. 2013. Youth and Revolution in Tunisia. Zed Books, London.

[23] Philip N. Howard and Muzammil M. Hussain. 2011. The Upheavals in Egypt and Tunisia: The Role of Digital Media. Journal of Democracy 22, 3 (2011), 35-48.

[24] Philip N. Howard and Malcolm R. Parks. 2012. Social Media and Political Change: Capacity, constraint, and consequence. fournal of Communication 62, 2 (2012), 359-362.

[25] IBRD. 2016. Data by Country. http://www.worldbank.org/en/country/tunisia/ overview

[26] Edward B. Keller and Jonathan L. Berry. 2003. The Influentials: One American in Ten Tells the Other Nine How to Vote, Where to Eat, and What to Buy. Free Press, New York, NY. viii, 353 p. pages.

[27] J. Kim, R. Wyatt, and Elihu Katz. 1999. News, talk, opinion, participation: the part played by conversation in deliberative democracy. Political Communication 16, 4 (1999), 361-385.

[28] Gilad Lotan, Erhardt Graeff, Mike Ananny, Devon Gaffney, Ian Pearce, and danah boyd. 2011. The revolutions were tweeted: Information flows during the 2011 Tunisian and Egyptian revolutions. International fournal of Communication 5 (2011), 1375-1405

[29] Nadia Marzouki and Hamza Meddeb. 2015. Tunisia: Democratic miracle or mirage? http://carnegie-mec.org/2015/06/11/ tunisia-democratic-miracle-or-mirage-pub- 60387
[30] Yousri Marzouki, Ines Skandrani-Marzouki, Moez Bejaoui, Haythem Hammoudi, and Tarek Bellaj. 2012. The contribution of Facebook to the 2011 Tunisian revolution: A cyberpsychological insight. Cyberpsychology, Behavior and Social Networking 15, 5 (2012), 237-244.

[31] Homero Gil de Zuniga James H. Liu Matthew Barnidge, Brigitte Huber. 2018. Social Media as a Sphere for "Risky" Political Expression: A twenty-country multilevel comparative analysis. The International Journal of Press/Politics 23, 2 (2018), 161-182.

[32] Rory McCarthy. 2019. The politics of consensus: al-Nahda and the stability of the Tunisian transition. Middle Eastern Studies 0, 0 (2019), 1-15. https://doi.org/10. 1080/00263206.2018.1538969 arXiv:https://doi.org/10.1080/00263206.2018.1538969

[33] Alexander Meikeljohn. 1948. Free Speech and its Relation to Self-Government. Harper \& Brothers, New York.

[34] Racha Mourtada and Fadi Salem. 2011. Facebook Usage: Factors and analysis. Report. Mohammed Bin Rashid School of Government.

[35] Patricia Moy and John Gastil. 2006. Predicting deliberative conversation: The impact of discussion networks, media use and political cognitions. Political Communication 23 (2006), 443-460

[36] Raymond J. Pingree. 2007. How messages affect their senders: A more general model of message effects and implications for deliberation. Communication Theory 17, 4 (2007), 439-461.

[37] H. Rojas and E. Puig-i Abril. 2009. Mobilizers mobilized: Information, expression, mobilization and participation in the digital age. Fournal of Computer-Mediated Communication 14, 4 (2009), 902-927.

[38] Fadi Salem and Racha Mourtada. 2014. Citizen engagement and public services in the Arab world: The potential of social media. Report. Mohammed Bin Rashid School of Government. http://www.arabsocialmediareport.com/ UserManagement/PDF/ASMR6_En_Final.pdf

[39] Peter M. Shane. 2004. Democracy online: the prospects for political renewal through the Internet. Routledge, New York, NY.

[40] Fred S. Siebert, Theodore Peterson, and Wilbur Schramm. 1963. Four Theories of the Press. University of Illinois Press.

[41] Aaron Smith, Sidney Verba, Henry Brady, and Kay Schlozman. 2009. The Internet and Civic Engagement. Report. Pew Internet \& American Life Project.

[42] Marc A. Smith, Lee Rainie, and Ben Schneiderman. 2014. Mapping Twitter Topic Networks: From polarized crowds to community clusters. Technical Report. Pew Internet \& American Life Project, Washington, DC.

[43] Kate Starbird and Leysia Palen. 2012. (How) Will the Revolution Be Retweeted?: Information Diffusion and the 2011 Egyptian Uprising. In Proceedings of the ACM 2012 Conference on Computer Supported Cooperative Work (CSCW'12). ACM, New York, NY, USA, 7-16. https://doi.org/10.1145/2145204.2145212

[44] Emily Thorson. 2014. Beyond opinion leaders: How attempts to persuade foster political awareness and campaign learning. Communication Research 41, 3 (2014), 353-74.

[45] TNS. 2015. Arab Social Media Report. Technical Report. Arab Social Media INfluencers Summit, Dubai Media City, Dubai UAE.

[46] Zeynep Tufekci and Deen Freelon. 2013. Introduction to the Special Issue on New Media and Social Unrest. American Behavioral Scientist 57, 7 (2013), 843-847. 
[47] Zeynep Tufekci and Christopher Wilson. 2012. Social Media and the Decision to Participate in Political Protest: Observations From Tahrir Square. Fournal of Communication 62, 2 (2012), 363-379. https://doi.org/10.1111/j.1460-2466.2012 01629.x

[48] Sidney Verba and Norman H. Nie. 1972. Participation in America: political democracy and social equality. Harper \& Row, New York, NY.

[49] Volker Wulf, Kaoru Misaki, Meryem Atam, David Randall, and Markus Rohde. 2013. 'On the Ground' in Sidi Bouzid: Investigating Social Media Use During the Tunisian Revolution. In Proceedings of the 2013 Conference on Computer Supported Cooperative Work (CSCW'13). ACM, New York, NY, USA, 1409-1418. https://doi.org/10.1145/2441776.2441935

[50] Homero Gil de Zuniga, Nakwon Jung, and Sebastian Valenzuela. 2012. Social media use for news and individuals' social capital, civic engagement and political participation. Journal of Computer Mediated Communication 17 (2012), 319-336. 